\section{Mediasi Sekuensial Sosial Media dan Digital Marketing pada Hubungan Brand Ambassador dengan Brand Trust Produk Scarlett Whitening}

\author{
Rahayu Lestari ${ }^{1}$ dan Beladdina An'nisa ${ }^{2}$ \\ Fakultas Ekonomi dan Bisnis, Universitas Nasional \\ Jakarta, Indonesia
}

\begin{abstract}
This study aims to examine the sequential mediation of the relationship between brand ambassadors and trust. Sequential mediation consisting of digital marketing and Instagram social media. The target population in this study are Scarlett Whitening product customers who use Instagram who are students of a private university in Jakarta. A sample of 96 was measured based on the rule of thumb of the experts The sampling technique used is convenience sampling. The method used in the research to test mediation uses a process macro with model no 6. Tests of validity, reliability and correlation are also described. The results show that brand ambassadors have an effect either directly or indirectly through sequential mediation (digital marketing and social media) on customer trust. Suggestion. Companies must be able to choose brand ambassadors who have good credibility because this not only has a direct effect on trust but also affects trust through increasing customer perceptions of digital marketing and social media used.
\end{abstract}

Keywords:

Brand ambassador, brand trust, digial marketing, social media. .

\section{Corresponding Author:}

Rahayu Lestari

Fakultas Ekonomi dan Bisnis, Universitas Nasional

Email: rahayulestari22@yahoo.com

(C) The Author(s) 2021

DOI: https://doi.org/10.36407/jmsab.v4i2.378

\section{CC}

CC BY: This license allows reusers to distribute, remix, adapt, and build upon the material in any medium or format, so long as attribution is given to the creator. The license allows for commercial use.
JMSAB 378

\author{
Research Paper \\ Marketing Management
}

Received: 22 Aug 2021

Accepted: 01 Oct 2021

Online: 31 Dec 2021

Jurnal Manajemen Strategi dan Aplikasi Bisnis, Vol 4, No. 2, 2021, pp. $543-552$

eISSN 2655-237X 


\section{PENDAHULUAN}

Persaingan usaha di bidang skincare pada globalisasi semakin aktif dan canggih. Persaingan pada usaha ini menciptakan kesempatan untuk bersaing tetapi juga menciptakan rintagan. Salah satu yang menjadi rintangan dan harus dihadapi oleh kompetitor pesaing adalah harus mencari cara yang terbaru untuk berada di posisi yang paling banyak dibutuhkan dan harus bisa mempertahankan pangsa pasar.Agar mempertahankan suatu produk di lingkungan kompetitor yang sangat kompetitif saat ini, pemiliki produk harus bisa menjalankan strategi pemasaran yang unik guna sebagai mengembangkan suatu produk yang memenuhi kebutuhan dan keinginan konsumen, tingkat persaingan dalam dunia bisnis produk kecantikan di Indonesia saat ini sangatlah ketat. perusahaan harus bisa melakukan strategi pemasaran di berbagai macam media baik secara langsung maupun secara digital. Sekarang ini bidang usaha mencari cara untuk mempertemukan konsumen dengan perusahaan melalui platfrom digital Penggunaan ponsel untuk mengakses internet dan jejaring sosial tidak terlepas dari jumlah pertumbuhan operator ponsel dengan menawarkan akses.Hal ini dapat dibuktikan dengan data berikut yang menunjukan jumlah pertumbuhan pengguna koneksi internet, ponsel, social media di indonesia pada tahun $2019-2021$.

Scarlett Whitening merupakan produk lokal yang telah teruji dan terdaftar di BPOM ini memiliki berbagai produk perawatan pribadi. Dalam penelitian ini berfokus pada semua produk perawatan dari Scarlett Whitening. PT. Motto Beringin Abadi sudah berjalan hampir 5 tahun di Indonesia. Walaupun produk Scarlett Whitening tidak memiliki website besar seperti merek Citra, Wardah, dan lainnya, produk Scarlett Whitening telah berhasil mendapatkan kepercayaan merek dari konsumennya melalui sosial media besar seperti Instagram dan Tik-Tok sehingga harus bisa bersaing dengan produk yang sama dan sudah lebih lama ada di marketplace seperti shopee dan lazada. Serta kualitas produk scarlett whitening dapat memenuhi harapan konsumen karena kualitas produk yang tinggi dan dapat diterima. Sebaliknya, jika tidak memenuhi harapan konsumen maka produk scarlett dianggap memiliki kualitas yang buruk maka dapat disimpulkan bahwa kualitas suatu produk harus memenuhi kebutuhan konsumen dan harapan terhadap suatu produk.

Literatur pemasaran mengenai kepercayaan pelanggan dekade saat ini banyak memfokuskan pada pemasaran digital. Bagaimana pemasaran digital mampu mempengaruhi kepercayaan pelanggan. Kepercayaan pelanggan dalam era pemasara digital banyak difokuskan ke website dan media sosial yang dipergunakan. Brand ambassador dipercaya akan mempengaruhi persepsi pelanggan mengenai website dan juga platform media sosial yang digunakan (Dwivedi dan Johnson, 2013). Media sosial khususnya instagram mampu mempengaruhi kepercayaan pelanggan (Irawan dan Hadisumarto, 2020). Digital marketing yang sering di selaraskan dengan website juga ikut andil dalam mempengaruhi kepercayaan pelanggan (Fahmi, Prayogi, dan Jufrizen, 2018). Maka dari itu penelitian ini berkontribusi menambah dukungan literatur pemasaran digital. Dengan tujuan penelitian menguji pengaruh mediasi sekuensial beberapa platform digital seperti website dan media sosial instagram pada hubungan brand ambassador dengan kepercayaan pelanggan.

\section{KAJIAN PUSTAKA}

\section{Brand Ambassador, Digital Marketing, dan Social Media Terhadap Trust}

Brand ambassador merupakan seseorang yang mampu menjadi juru bicara, memberikan informasi yang terperinci atas gambaran dan kualitas suatu produk serta memberikan kesan yang 
baik dari citra merek (Soehadi, 2015). Indikator Karakteristik dari brand ambassador dikenal dengan ViSCAP yang terbentuk dari kepopuleran (visiibility), kredibilitas (crediibility), daya tarik (attraction), dan kekuasaan (power) yang ada pada selebritas yang mewakili produk atau jasa sehingga dapat membujuk calon pelanggan dalam membeli produk atau jasa (Percy \& Rossiter, 2015).

Brand ambassador yang sering juga di istilahkan celebrity endorse ataupun celebrity credibility ini memliki hubungan dengan kepercayaan pada merek (Dwivedi dan Johnson, 2013; Restu dkk., 2020). Hubungan celebrity credibility terhadap kepercayaan pada merek ini terbentuk dikarenakan konsumen cenderung membalas dengan terlibat dalam jangka panjang perilaku relasional dengan merek yang didukung oleh pilihan selebriti yang kredibel. Mereka terlibat dalam perilaku seperti itu sehingga mereka terus menerima (memperkuat) manfaat definisi diri tersebut (Dwivedi dan Johnson, 2013). Hubungan ini juga dijelaskan karena kepercayaan merupakan salah satu variabel sikap. Celebrity credibility atapun ambassador credibility mempengaruhi terhadap sikap pelanggan pada merek tersebut (Sugiharto dan Ramadhana, 2018) antara lain meningkatkan pengaruh positif pada merek (Sugiharto dan Ramadhana, 2018), membuat pelanggan lebih mudah mengingat merek (Singh dan Banerjee, 2018). Jadi disarankan agar endorsement menampilkan selebriti dengan kredibilitas yang lebih tinggi menyebabkan dampak yang menguntungkan pada sikap konsumen terhadap iklan. Jadi, seorang selebriti dengan kredibilitas yang lebih tinggi dapat menyebabkan dampak yang menguntungkan pada sikap (kepercayaan) konsumen terhadap merek yang diiklankan (Singh dan Banerjee, 2018).

$\mathrm{H} 1$ : Brand ambassador berpengaruh positif terhadap trust (kepercayaan)

Pemasaran digital adalah bentuk bisnis perusahaan sebagai praktik strategi pemasaran yang menggunakan satu atau lebih dari bentuk media elektronik atau teknologi digital untuk mempromosikan produk atau layanan secara online (Hassan, 2014; Rusmanto, 2017). Definisi ini sejalan definisi (Saputra, 2020) menetapkan bahwa digital marketing adalah suatu bentuk upaya bisnis untuk menghasilkan preferensi dan mempromosikan produk dengan tujuan budget terukur melalui teknologi digital. Platform-paltform yang sering dipergunakan dan diterapkan sebagai digital marketing antara lain website, social networking, e-mail marketing dan juga customer relationship marketing (Ryan dan Jones, 2012). Situs web adalah salah satu bentuk penyajian informasi yang mengarahkan secara langsung kepada pelanggan terkait sumber informasi mengenai produk atau jasa.

Pengukuran website bisa dilihat dari kemampuan sosial web dan kualitas web tersebut yaitu ketersediaan informasi, interaktif, sopan, lengkap dan kekinian serta membantu pelanggan. Website yang dipersepsikan berkualitas oleh pelangggan akan menarik pelanggan dan membuat pelanggan semakin percaya terhadap merek tersebut (Fahmi, Prayogi, dan Jufrizen, 2018; Novinoa dan Sutopo, 2017). Tampilan web yang dipersepsikan makin baik oleh pelanggan akan meningkatkan kepercayaan pelanggan terhadap merek (Japarianto dan Adelia, 2020).

H2: Digital marketing berpengaruh positif terhadap trust

Menurut (Santoso, 2017), Social Media Instagram Marketing adalah strategi pemasaran digunakan sebagai membuat kesadaran, penetapan, perhatian, dan tindakan terhadap suatu merek, produk, bisnis, berkelompok maupun individu baik secara langsung dan tidak langsung dengan memanfaatkan platform Instagram. Adanya pemasaran sosial media instagram membuat lebih mudah bagi komersial untuk melakukan interaksi terhadap konsumennya secara online. Budget untuk melakukan pemasaran tidak tinggi dan tidak mempunyai batas waktu untuk terhubung ke internet. Social media memiliki peran ketika aktivitas pemasaran perusahaan 
membangun sebuah hubungan individu dengan konsumen dan memberi perusahaan akses ke klien.

Aktivitas social media marketing yang dilihat berdasarkan entertainment, interaction, trendiness, customization, dan word-of-mouth pada instagram memiliki pengaruh yang positif terhadap kepercayaan merek (Irawan dan Hadisumarto, 2020). Sosial media instagram berpengaruh terhadap kepercayaan merek (Tong, 2020). Maka dari itu diajukan hipotesis sebagai berikut:

H3: Social media berpengaruh positif terhadap trust

Pemediasian Pengaruh Brand Ambassador terhadap TrustBelum terdapat penelitian yang mengkhususkan untuk meneliti pengaruh pemediasian terutama mediasi sekuensial brand ambassador terhadap kepercayaan merek. Kredibilitas perwakilan merek atau perusahaan ini yang sering diwakilkan pada selebriti membangun kedekatan dengan pelanggan. Kedekatan yang mampu mempengaruhi pemikiran pemikiran yang lebih positif pada merek dan yang meliputinya seperti cara dan alat yang dipergunakan yaitu website merek tersebut(Dwivedi dan Johnson, 2013). Yang mana website juga akan mempengaruhi kepada cara pelanggan menggunakan dan merasakan aplikasi di dalamnya seperti instagram(Dwivedi dan Johnson, 2013). Dan dari persepsi instagram yang menyenangkan dalam benak konsumen maka akan mempengaruhi kepercayaan konsumen terhadap merek tersebut(Irawan dan Hadisumarto, 2020; Tong, 2020). Oleh karena itu ditariklah hipotesis sebagai berikut:

H4: Brand Ambassador berpengaruh tidak langsung terhadap trust dengan dimediasi oleh digital marketing

H5: Brand Ambassador berpengaruh tidak langsung terhadap trust dengan dimediasi oleh social media

H6: : Brand Ambassador berpengaruh tidak langsung terhadap trust melalui pemediasian sekuensial digital marketing dan social media

\section{Model Penelitian}

Model yang diajukan dalam penelitian ini setelah mengembangkan hipotesis yang ada, adalah sebagai berikut:

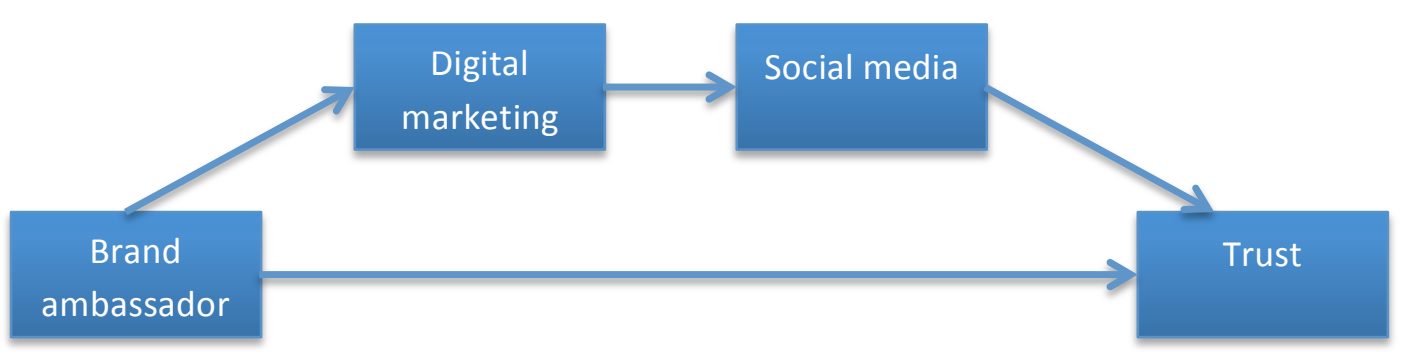

\section{Gambar 1. Model Penelitian}

\section{METODE}

\section{Populasi dan Sampel}

Populasi yang dituju dalam penelitian ini adalah konsumen produk Scarlett Whitening yang mempergunakan instagram. Penentuan ukuran sampel dengan mempergunakan rule of thumb para ahli (Sekaran, 2017) yang menyatakan bahwa penelitian sosial yang baik ukuran sampel di 
antara 30-500. Kedua ukuran sampel diwakili minimal 10 per variabel. Dalam penelitian ini terdapat 4 variabel sehingga ukuran sampel minimal adalah 40 responden. Ketiga, ukuran sampel dengan ketentuan jumlah item dalam pengukuran, minimal 5 responden mewakili 1 item. Dalam penelitian ini pertanyaan terbanyak pada variabel sosial media dengan 6 item. Jadi ukuran minimal sampel adalah 30 sampel. Oleh karena itu ukuran sampel 96 dirasa sangat mencukupi ketentuan ukuran sampel sesuai dengan aturan para ahli. Teknik pengambilan sampel dengan menggunakan convenience sampling. Peneliti membagikan kuesioner kepada konsumen yang bisa diraih.

\section{Metode Pengukuran Data}

Pengumpulan data penelitian ini mempergunakan data primer dengan mengedarkan kuesioner. Peneliti mengedarkan kuesioner kepada para konsumen yang mempergunakan instagram dan yang bisa diraih oleh peneliti. Kuesioner yang diedarkan menggunakan skala likert pengukuran 1 sampai dengan 5 yang merupakan tingkat persetujuan. Variabel brand ambassador diukur dengan skala yang diadaptasi dari Singh and Banerjee (2018) dengan 5 item mengukur kredibilitas brand ambassador. Pertanyaan sejumlah 6 item diadaptasi dari Khan digunakan untuk mengukur variabel sosial media. Pengukuran variabel digital marketing mempergunakan pengadaptasian skala dari Wang dkk. (2007). Pengukuran ini menjelaskan mengenai website socialness, yang mengukur ketersediaan informasi, interaktif, sopan, lengkap dan kekinian serta membantu pelanggan. Untuk kepercayaan diukur dengan mendefinisikan kepercayaan terhadap brand dalam pembelian online menggunakan dari Tuteja dkk.

\section{Metode Analisis}

Pengujian hipotesis mediasi moderasi mempergunakan macro process V3.5 model no 6 yang dibantu dengan alat SPSS 26 dan Process v3.5. Sebelumnya pengujian uji validitas dilakukan dengan analisis faktor. Uji reliabilitas dengan cronbach Alpha. Semuanya dilakukan dengan bantuan SPSS 26.

\section{HASIL DAN PEMBAHASAN}

\section{Instrumen Penelitian}

Hasil pengujian Confirmatory Factor Analysis (CFA) memperlihatkan nilai Kaiser Meyer Olkin Measure Sampling Adequacy (KMO MSA) semua variabel memiiliki nilai yang baik diatas 0,6 dengan tingkat sig di bawah 0,05 (Nunnally, 2017). Nilai faktor loading hampir semua item memiliki nilai di atas 0,5. Hanya satu item pada variabel social media yaitu item ke enam yang memiliki nilai loading factor di bawah 0,5, oleh karena itu di hapus dari penelitian ini. Tabel 1 memperlihatkan hasil pengujian instrument.

Dan Semua variabel memenuhi dengan memiiki tingkat konsistensi internal yang baik atau reliabel. Hasil pengujian reliabilitas dengan Cronbach's Alpha memperlihatkan bahwa semua variabel sangat reliabel dengan nilai di atas 0,9. Variabel brand ambassador memiliki nilai Cronbach's Alpha 0,933, variabel digital marketing nilai Cronbach's Alpha sebesar 0,920.Nilai Cronbach's Alpha untuk variabel social media instagram sebesar 0,928. Sedangkan variabel kepercayaan mendapatkan nilai Cronbach's Alpha sebesar 0,938. 


\begin{tabular}{|c|c|c|c|c|}
\hline \multirow[b]{2}{*}{ item } & \multicolumn{4}{|c|}{ variabel } \\
\hline & $\begin{array}{l}\text { Brand } \\
\text { Ambassador(BA) }\end{array}$ & $\begin{array}{l}\text { Digital marketing } \\
\text { (DM) }\end{array}$ & Sosial media (SM) & Trust (T) \\
\hline BA1 & 0,822 & & & \\
\hline BA2 & 0,912 & & & \\
\hline BA3 & 0,908 & & & \\
\hline BA4 & 0,920 & & & \\
\hline BA5 & 0,894 & & & \\
\hline DM1 & & 0,856 & & \\
\hline DM2 & & 0,849 & & \\
\hline DM3 & & 0,853 & & \\
\hline DM4 & & 0,890 & & \\
\hline DM5 & & 0,912 & & \\
\hline SM1 & & & 0,858 & \\
\hline SM2 & & & 0,892 & \\
\hline SM3 & & & 0,889 & \\
\hline SM4 & & & 0,883 & \\
\hline SM5 & & & 0,889 & \\
\hline $\mathrm{T} 1$ & & & & 0,927 \\
\hline T2 & & & & 0,875 \\
\hline T3 & & & & 0,932 \\
\hline $\mathrm{T} 4$ & & & & 0,942 \\
\hline KMO MSA & 0,881 & 0,829 & 0,888 & 0,857 \\
\hline $\begin{array}{l}\text { Cronbach } \\
\text { Alpha }\end{array}$ & 0,933 & 0,920 & 0,928 & 0,938 \\
\hline
\end{tabular}

Sumber data diolah SPSS 26, 2021

\section{Uji Asumsi}

Sebelum melakukan pengujian hipotesis mempergunakan Process, peneliti terlebih dahulu melakukan pengujian asumsi. Hal ini dilakukan untuk menambah keyakinan pada interpretasi hasil penelitian ini. Uji asumsi yang dilaksanakan adalah normalitas, heterokedastisitas, dan multikolinieritas. Pengujian normalitas menggunakan metode uji kolmogorov smirnov. Hasil pengujian memperlihatkan nilay asymp. Sig nya di $0,200>0,05$, hal ini menyatakan bahwa data berdistribusi normal. Hasil pengujian uji Glesjer untuk melihat apakah data terkena heterokedastisitas, memberikan hasil semua variabel bebas yaitu brand ambassador, digital marketing dan social media tidak signifikan terhadap nilai absolute residualnya. Pengujian Multikolinieritas memperlihatkan tidak terjadi gejala multikolinieritas dengan nilai VIF di $<10$.

\section{Uji Statistik Deskriptif dan Korelasi}

Sebelum melakukan pengujian hipotesis, pengujian untuk melihat rata-rata nilai variabel dan juga korelasi antar variabel dilakukan. Tabel 2 memperlihatkan hasil rata-rata (mean) dan juga korelasi zero order.

Tabel 2. Statistik Deskriptif dan Korelasi

\begin{tabular}{lllllll}
\hline & Mean & SD & T & BA & DM & SM \\
T & 4,292 & 0,825 & 1,000 & & & \\
BA & 4,006 & 0,979 & $0,771^{* *}$ & 1.000 & & \\
DM & 4,442 & 0,695 & $0,772^{* *}$ & $0,719^{* *}$ & 1,000 & \\
SM & 4,390 & 0,732 & $0,893^{* *}$ & $0,768^{* *}$ & $0,842^{* *}$ & 1,000 \\
\hline
\end{tabular}

${ }^{* *} \mathrm{p}<0,01 ;{ }^{*} \mathrm{p}<0,05$

Sumber Data diolah 2021

Korelasi antar variabel menunjukkan bahwa brand ambassador, digital marketing dan social media memiliki hubungan yang signifikan dengan kepercayaan pada merek. Hubungan brand 
ambassador dan digital marketing pada kepercayaan merek memiliki hubungan yang kuat. Hubungan sangat kuat terdapat pada hubungan social media dengan kepercayaan pada merek serta hubungan social media dengan digital marketing dengan nilai korelasi berturut-turut 0,893 dan 0,842 .

\section{Uji Hipotesis Pengaruh Langsung}

Pengaruh langsung yang diuji menggunakan Process V3.5 terlihat pada tabel 3. Hasil memperlihatkan dukungan pada hipotesis yang diajukan dalam penelitian ini.

Tabel 3. Pengujian Pengaruh Langsung

\begin{tabular}{lllllll} 
Hipotesis & Hubungan & coeff & $\mathrm{p}$ & LLCI & ULCI & Keterangan \\
\hline $\mathrm{H} 1$ & $\mathrm{BA} \rightarrow \mathrm{T}$ & 0,1719 & 0,005 & 0,0522 & 0,2915 & Didukung \\
$\mathrm{H} 2$ & $\mathrm{DM} \rightarrow \mathrm{T}$ & 0,0206 & 0,839 & $-0,1794$ & 0,2205 & Tidak Didukung \\
$\mathrm{H} 3$ & $\mathrm{SM} \rightarrow \mathrm{T}$ & 0,8150 & 0,000 & 0,6086 & 1,0214 & Didukung \\
& & & & & & \\
\hline $\mathrm{R}^{2}$ & & 0,8159 & & & & \\
$\mathrm{~F}$ & & 135,9327 & 0,000 & & & \\
\hline
\end{tabular}

Sumber Data diolah 2021

Tabel 3, menunjukkan bahwa model pengaruh langsung kepada kepercayaan dengan tiga variabel brand ambassador, digital marketing dan social media sebagai variabel bebas merupakan model yang baik. hal ini ditunjukkan dengan nilai $F$ sebesar 135, 9327 pada nilai p 0,000<0,05. Ketiga variabel mampu menjelaskan pengaruh kepada kepercayaan pelanggan sebesar 81,6\% sedangkan sisanya sebesar 18,4\% varians terhadap kepercayaan pelanggan dijelaskan oleh variabel lain dan model yang lain yang tidak diungkapkan dalam penelitian ini.

Hipotesis 1 yang menyatakan brand ambassador memiliki pengaruh terhadap kepercayaan pada merek (Trust) didukung oleh data. Data yang mendukung hal ini terlihat pada nilai p sebesar $0,000<0,05$ dengan nilai coeff sebesar 0,1719 . Pelanggan akan makin percaya kepada merk ketika brand ambbasador semakin ditingkatkan atau semakin kredibel. Pelanggan yang mempersepsikan seorang ambassador ataupun selebritis yang mampu dipercaya, kredibel akan membawa pengaruh positif terhadap pemikiran pelanggan pada merek tersebut (Singh dan Banerjee, 2018). Hal ini terbentuk karena adanya koneksi yang erat yang dibentuk oleh selebritis atau ambassador tersebut dengan para konsumen (Dwivedi, Johnson dan McDonald, 2015).

Hipotesis 2 tidak diukung oleh data. Hal ini memberikan arti bahwa digital marketing tidak signifikan berpengaruh terhadap kepercayaan. Dibuktikan dengan data nilai p 0,839 >0,05. Digital marketing dalam penelitian ini didefinisikan sebagai website yang lebih sosial atau ramah, dan memberikan informasi yang dibutuhkan kepada pelanggan tidak dipersepsikan oleh pelanggan sebagai hal yang mampu membuat mereka percaya terhadap merek tersbut. Hal ini sesuai dengan penelitian dari Piarna (2014) bahwa sumber informasi tidak mempengaruhi kepada tingkat kepercayaan pelanggan.

Seiring ditingkatkannya social media instagram maka kepercayaan pelangganpun meningkat. Hal ini mengungkapkan dukungan kepada hipotesis 3. Dengan bukti data nilai $p$ $0,000<0,05$. Fitur atribut website berpengaruh terhadap kepercayaan pelanggan dan pengaruh ini besar kecilnya tergantung dari kualitas produk dan harga produk tersebut (Sebastianelli dan Tamimi, 2018). Website yang dipersepsikan oleh pelanggan semakin berkualitas mempengaruhi pemikiran kredibilitas website dan pada akhirnya akan meningkatkan kepercayaan pelanggan (Japarianto dan Adelia, 2020; Piarna, 2018). Penemuan ini juga mendukunga hal tersebut, bahwa 
digital marketing yang diukur dengan website socialness berpengaruh terhadap kepercayaan pelanggan.

\section{Uji Hipotesis Mediasi}

Hasil pemediasian dalam penelitian ini ditunjukkan melalui tabel 4. Pemediasian diuji dengan process, memperlihatkan hasil beberapa jalur mediasi yang menghubungkan brand ambassador dengan kepercayaan pelangggan.

Tabel 4. Pengujian Pengaruh Mediasi

\begin{tabular}{llllll} 
Hipotesis & Hubungan & Effect & BootLLCI & BootULCI & Keterangan \\
\hline $\mathrm{H} 4$ & $\mathrm{BA} \rightarrow \mathrm{DM} \rightarrow \mathrm{T}$ & 0,0124 & $-0,1392$ & 0,1615 & Tidak didukung \\
$\mathrm{H} 5$ & $\mathrm{BA} \rightarrow \mathrm{SM} \rightarrow \mathrm{T}$ & 0,2435 & 0,0877 & 0,4031 & Didukung \\
$\mathrm{H} 6$ & $\mathrm{BA} \rightarrow \mathrm{DM} \rightarrow \mathrm{SM} \rightarrow \mathrm{T}$ & 0,3114 & 0,1519 & 0,4941 & Didukung \\
& & & & & \\
\hline $\mathrm{R}^{2}$ & & 0,5947 & & & \\
$\mathrm{~F}$ & & 137,9230 & 0,000 & & \\
\hline
\end{tabular}

Sumber Data diolah 2021

Tabel 4 menunjukkan bahwa model merupakan model yang baik dengan nilai $\mathrm{F}$ sebesar 137,9230 dengan nilai $p$ sebesar $0,000<0,05$. Meskipun daya penjelas hanya sebesar $59,47 \%$ lebih kecil dibandingkan dengan model ketika berpengaruh langsung dengan daya penjelas 81,59\% variabel menjelaskan pengaruhnya terhadap kepercayaan. Tetapi nilai F di model mediasi lebih besar dibandingkan pada model pengaruh langsung. Hal ini perlu menjadi perhatian untuk kajian berikutnya.

Hipotesis 4 tidak didukung. Hipotesis 4 yang menyatakan brand ambassador memiliki pengaruh terhadap kepercayaan dengan di mediasi oleh digital marketing tidak signifikan. Hasil pengaruh langsung brand ambassador terhadap kepercayaan terbukti mampu mempengaruhi secara langsung tetapi pengaruh tidak langsungnya ke kepercayaan melalui mediasi digital marketing ternyata tidak memiliki pengaruh yang signifikan. Hal ini dikarenakan digital marketing tidak signfikan mempengaruhi kepercayaan pelanggan. Yang sesuai dengan penelitian Piarna (2014) bahwa sumber informasi tidak mempengaruhi kepercayaan pelanggan.

Hipotesis 5 pemediasian social media pada hubungan brand ambassador terhadap kepercayaan pelanggan terbukti didukung oleh data. Hasil dari tabel 4 memperlihatkan ukuran $\mathrm{b}$ sebesar 0,2435, 95\% CI (0,0877: 0,4031). Hal ini mendukung bahwa brand ambassador yang dipersepsikan pelanggan dapat dipercaya, mampu mempengaruhi pada perasaan mengenai platform sosial media seperti instagram ((Dwivedi, Johnson dan McDonald, 2015), yang pada akhirnya akan meningkatkan kepercayaan pelanggan (Japarianto dan Adelia, 2020; Piarna, 2018).

Sekuensial mediasi brand ambassador akan mempengaruhi digital marketing selanjutnya berpengaruh terhadap media sosial kemudian diteruskan dari social media mempengaruhi kepada kepercayaan, hal ini didukung oleh data. Hal ini merupakan penjabaran dari hipotesis 6. Mediasi sekuensial terbukti dengan nilai $\mathrm{b}=0,3114,95 \% \operatorname{CI}(0,1519: 0,4941)$. Hal ini sesuai dengan definisi brand ambassador yang merupakan juru bicara yang mampu memberikan informasi dan membawa citra yang baik bagi merek dan perusahaan (Soehadi, 2015). Sesuai dengan hasil seorang brand ambassador yang semakin baik akan semakin mampu mempengaruhi pelanggan dalam hal persepsi informasi dan persepsi mengenai alat komunikasi lainnya berujung pada kepercayaan dan merek,

\section{KESIMPULAN DAN IMPLIKASI}

Sesuai dengan hasil dan pembahasan maka dapat disimpulkan bahwa brand ambassador mampu berpengaruh secara langsung terhadap kepercayaan pelanggan dan berpengaruh tidak langsung 
dengan melalui mediasi sekuensial yaitu digital marketing ke media sosial. Maka dari itu hasil ini memberikan implikasi praktis kepada perusahaan, pertama perusahaan perlu merekrut ambassador dengan hati-hati dan cermat dikhususkan dengan memilih ambassador yang dipercaya oleh pelanggan memiliki kredibilitas yang baik. Karena hal ini akan mempengaruhi secara langsung dan tidak langsung kepada kepercayaan pelanggan terhadap merek dan perusahaan tersebut. Kedua, penggalakan media sosial seperti instagram perlu ditingkatkan seiring dengan ambassador yang kredibel, karena social media juga mampu berpengaruh langsung terhadap kepercayaan dan social media juga merupakan pemediasi bagi brand ambassador terhadap kepercayaan. Penggunaan sosial media yang terpantau, dijaga kualitas dan juga lalu lintas untuk berkomunikasi dengan pelanggan dibuat lebih friendly, dan mudah dijangkau dengan respon yang cepat tanggap. Dan diketahui kepercayaan terhadap merek sangat penting untuk menciptakan citra merek yang pada akhirnya menaikkan minat mebeli kembali (Chairudin dan Sari, 2021).

\section{Keterbatasan dan Saran}

Hasil penelitian menunjukkan model pengaruh langsung memberikan daya penjelas yang lebih besar dibandingkan model pemediasian. Hal ini ke depan perlu lebih diteliti dan dikaji lebih dalam terutama dalam membandingkan model keduanya. Keterbatasan kedua adalah penelitian dengan populasi yang terbatas pada pelanggan satu produk saja, sehinggga penerapan penelitian ini juga sangat terbatas. Penelitian ke depan diharapkan dapat menambah variasi populasi. Keterbatasan ketiga, kemungkinan terjadinya bias dikarenakan penelitian menggunakan pengukuran self rated. Maka dari itu penelitian selanjutnya sebaiknya mempergunakan cara-cara untuk meminimalkan terjadinya bias seperti pengedaran kuesioner dengan waktu yang terpisah. Dan menggunakan pengujian untuk melihat apakah bias dalam penelitian sangat berarti atau tidak, semisal dengan pengujian Harman single factor.

\section{REFERENSI}

Chairudin, A., \& Sari, S.R. (2021). Model Hubungan Citra Merek dan Minat Beli Ulang : Peran Kepuasan Pelanggan dan Kesetiaan Pelanggan. Oikonomia: Jurnal Manajemen, 17(2), 112-126. http://dx.doi.org/10.47313/oikonomia.v17i2.1259

Dwivedi, A., \& Johnson, L. W. (2013). Trust-Commitment as a Mediator of the Celebrity EndorserBrand Equity Relationship in a Service Context. Australasian Marketing Journal, 21(1), 36-42. https://doi.org/10.1016/j.ausmj.2012.10.001

Dwivedi, A., Johnson, L.W. and McDonald, R.E. (2015), "Celebrity endorsement, self-brand connection and consumer-based brand equity", Journal of Product \& Brand Management, Vol. 24 No. 5, pp. 449-461. https://doi.org/10.1108/JPBM-10-2014-0722

Fahmi, M., Prayogi, M. A., Jufrizen. (2018). Peran kepercayaan pelanggan dalam memediasi pengaruh kualitas website terhadap loyalitas pelanggan online shop. Jurnal Riset Sains Manajemen, 2(3), 121- 130. DOI: 10.5281/zenodo.1477534

Hasan, A., 2013:67. Marketing dan Kasus-Kasus Pilihan. Yogyakarta: Center for Academic Publishing Service.

Irawan, A.D., \& Hadisumarto, A.D. (2020). Pengaruh Aktivitas Social Media Marketing Terhadap Brand Trust, Brand Equity, dan Brand Loyalty Pada Platform Social Media Instagram, Jurnal Manajemen dan Usahawan Indonesia, 43 (1),44-58.

Japarianto, E., \& Adelia, S. (2020). Pengaruh Tampilan Web Dan Harga Terhadap Minat Beli Dengan Kepercayaan Sebagai Intervening Variable Pada E-Commerce Shopee. Jurnal Manajemen Pemasaran, 14(1). DOI: https://doi.org/10.9744/pemasaran.14.1.35-43 
Novinoa, G., \& Sutopo, S. (2017). Analisis Pengaruh Kualitas Pelayanan, Kualitas Website Terhadap Kepuasan, Kepercayaan, Dan Niat Pembelian Kembali (Studi pada toko online Blibli.com). Diponegoro Journal of Management, 6(4), 350-359. Retrieved from https://ejournal3.undip.ac.id/index.php/djom/article/view/17987

Percy \& Rossiter, 2015: 30. Pengaruh brand ambassador, citra merek dan lolyalitas konsumen terhadap citra merek.

Piarna, R. (2014). Pengaruh Sumber Informasi dan Kualitas Website terhadap Kepercayaan Pelanggan dalam Menentukan Keputusan Bertransaksi pada E-commerce (Studi pada Pelanggan Ecommerce di Indonesia). Jurnal Aplikasi Manajemen, 12(1), pp. 10-21. Retrieved from https://jurnaljam.ub.ac.id/index.php/jam/article/view/616

Restu, W., Ramdan, A., Sunarya, E., \& Santika, R. (2020). Analisis Iklan Ruang Guru Dan Brand Ambassador Dalam Meningkatkan Kepercayaan Konsumen Pengguna Ruang Guru. Syntax Idea, 2(9), 690-695. doi:10.36418/syntax-idea.v2i9.567

Rusmanto, 2017:47. Pengantar Digital Marketing: Modul Manajemen Berbasis IT. Depok: Sekolah Tinggi Teknologi Terpadu Nurul Fikri.

Saputra, G. W. \&. A. I. G. A. K. S., 2020:9. Pengaruh Digital Marketing, Word of Mouth, Dan Kualitas Pelayanan Terhadap Keputusan Pembelian. E-Jurnal Manajemen Universitas Udayana, p. 9.

Santoso, 2017. Social Media Marketing. s.l.:s.n.

Sebastianelli, R. and Tamimi, N. (2018), "E-tailer website attributes and trust: understanding the role of online reviews", Online Information Review, Vol. 42 No. 4, pp. 506-519. https://doi.org/10.1108/OIR-02-2016-0039

Singh, R. P., \& Banerjee, N. (2018). Exploring the Influence of Celebrity Credibility on Brand Attitude, Advertisement Attitude and Purchase Intention. Global Business Review, 19(6), 16221639. https://doi.org/10.1177/0972150918794974

Sugiharto, S.A., \& Ramadhana, M.R. (2018). Pengaruh Kredibilitas Influencer Terhadap Sikap Pada Merek (Studi pada Mahasiswa Fakultas Komunikasi dan Bisnis Universitas Telkom). Jurnal Ilmu Politik dan Komunikasi, 8(2).

Soehadi, 2015:13. Manajemen Kinerja.

Tong, T.K.B.P. (2020). Analisa Pengaruh Social Media Marketing Terhadap Repurchase Intention Melalui Brand Trust Sebagai Variabel Mediasi Pada Instagram Adidas Indonesia Di Surabaya. Jurnal Strategi Pemasaran, 7(1). Retrieved from https://publication.petra.ac.id/index.php/manajemen-pemasaran/article/view/1006

\section{Competing interests}

The authors declare that they have no competing interests.

\section{Funding}

